\title{
Investigation of beetle species that carry the pine wood nematode, Bursaphelenchus xylophilus (Steiner and Buhrer) Nickle, in China
}

\author{
Yang Wang $^{1,2} \cdot$ Fengmao Chen ${ }^{1,2} \cdot$ Lichao Wang $^{1,2}$. \\ $\operatorname{Min} \mathbf{L i}^{1,2}$
}

Received: 17 October 2019 / Accepted: 29 December 2019 / Published online: 18 May 2020

(C) The Author(s) 2020

\begin{abstract}
In order to found new carriers of pine wood nematode (PWN), Bursaphelenchus xylophilus, beetles were collected from pine wilt disease-affected areas in six provinces in China. A total of 8830 beetles of 29 species was collected and examined to determine whether they were PWN carriers. Eight species were identified as carriers. Results included the first worldwide report of Monochamus nigromaculatus, Semanotus sinoauster, and Uraecha angusta being carriers of PWN, and the first report from China of Arhopalus rusticus carrying PWN. Monochamus alternatus was commonly collected in all six provinces and was the dominant species in four inland affected areas and A. rusticus was dominant in two coastal affected areas. The species varied between different neighboring regions in the same province. The
\end{abstract}

Project funding: The work was supported by the National Key Research and Development Program of China (Grant Number: 2017YFD0600104), and the Shenyang Science and Technology Planning Project (Grant Number:18-400-3-03).

The online version is available at http://www.springerlink.com.

Corresponding editor: Tao $\mathrm{Xu}$.

Electronic supplementary material The online version of this article (https://doi.org/10.1007/s11676-020-01146-2) contains supplementary material, which is available to authorized users.

Fengmao Chen

cfengmao@njfu.edu.cn

1 Collaborative Innovation Center of Sustainable Forestry in Southern China, College of Forestry, Nanjing Forestry University, Nanjing 210037, People's Republic of China

2 Institute of Forest Protection, College of Forestry, Nanjing Forestry University, Nanjing 210037, People's Republic of China distribution of the same species varied considerably over different regions.

Keywords Beetle $\cdot$ Carrier $\cdot$ Pine wilt disease $\cdot$ Pine wood nematode $\cdot$ Vector

\section{Introduction}

Pine wilt disease (PWD), caused by the pine wood nematode (PWN), Bursaphelenchus xylophilus (Steiner and Buhrer) Nickle, is the most destructive disease affecting pine species in China and causes significant economic losses (Yang et al. 2003). PWD is regarded as an "incurable disease" because infected pines die rapidly and there are no effective measures available for its treatment. PWN is native to North America where it usually damages only exotic (i.e., introduced nonnative) pine species, but it has also spread to countries in Asia such as Japan, China and South Korea, and to European countries of Portugal, and Spain (Zhao et al. 2008; Vicente et al. 2012). PWD spreads rapidly and is extremely difficult to prevent and control. Therefore, PWD has been listed as a quarantine disease in many countries. Studies have suggested that at least 45 insect species may carry PWN, belonging to the families Cerambycidae, Buprestidae, Curculionidae, Scolytidae, and Termitidae (Zhang et al. 2007). However, not all insect species that carry PWN can transmit it; only ones with life histories matching that of PWN may become vectors. The activities of vector insects, especially feeding and oviposition behaviors, are the basic modes responsible for the natural transmission of PWN (Togashi and Shigesada 2006). Of the 45 insect species known to carry PWN, only 13 act as vectors. These 13 insect species all belong to the family of long-horned beetles, Monochamus spp. (Cerambycidae) (Zhang et al. 2007). The regional 
distribution of these 13 beetle species are Monochamus alternatus Hope, Monochamus saltuarius Gebler, Monochamus grandis Waterhouse, and Monochamus sutor Linnaeus in Asia, and Monochamus galloprobincialis Olivier and $M$. sutor in Europe, with the remaining eight species common to North America (Sousa et al. 2001; Zhang et al. 2007). Vector beetles that spread PWN are often dominant species in the local area, e.g., the main vector of PWN in Asia is M. alternatus (Chai and Jang 2003), in North America, it is Monochamus carolinensis Olivier (Linit et al. 1983; Chai and Jang 2003), and in Europe, it is M. galloprobincialis (Sousa et al. 2001). Monochamus spp. beetles are recognized as the most important vectors of PWN (Kim et al. 2003; Ning et al. 2004). M. alternatus (Chai and Jang 2003) and M. saltuarius (Yu and $\mathrm{Wu} 2018$ ) are the known vectors of PWN in China. Previous studies have also reported potential PWN vector beetles. Acanthocinus griseus Fabricius, A. gundaiensis Kano (Xu et al. 1993), Arhopalus rusticus Linnaeus (Linit et al. 1983), Aromia bungii Faldermann (Wang et al. 1985) have been reported to be carriers of PWN in China. Asemum striatum Linnaeus, Corymbia succedanea Lewis, Spondylis buprestoides Linnaeus, Uraecha bimaculata Thomoson have been identified as PWN carriers in Japan (Zhang et al. 2007), with these as well as the species of beetle in China. Numerous studies have investigated the beetle vectors of PWN but these studies may not have been thorough and it is possible that some carriers have not been identified and may be potential PWN vectors. To better understand the species of beetles that carry PWN in China, beetles were collected from PWD-affected areas and identified the presence of PWN by real-time polymerase chain reaction (PCR), also known as quantitative polymerase chain reaction (qPCR) (Chen et al. 2007). Identifying the beetle species that carry PWN is important for reducing or limiting the spread of PWN and for improving the level of control. Thus, the results of this study should provide a theoretical basis for the control of PWD.

\section{Materials and methods}

Between May and September 2019, beetles were collected from PWD-affected areas in Dalian, Liaoning Province, Linshui, Sichuan Province, Huangshan, Anhui Province, Zhashui and Foping in Shaanxi Province, Qingdao, Shandong Province and Renhuai, Guizhou Province (Fig. 1). Ten traps (Supplementary: Fig. S1) with APF-I lure (CHEN KAN AGROFORESTRY, Xiamen, China) used to trap beetles were hung in each affected area. Numbers and species were recorded every three days. Photographs of the beetles were taken with a Zeiss stereoscopic microscope (SteREO Discovery.V20, Carl Zeiss, Göttingen, Germany).

Each beetle was placed in a surface-sterilized mortar, frozen in liquid nitrogen, ground to a powder and transferred to a 2-mL Eppendorf tube with $1.5 \mathrm{~mL}$ of nematode lysis solution (Zhang et al. 2017) and $5 \mu \mathrm{L}$ of protease K (Takara, Dalian, China). The mixture was then subjected to centrifugation at $2000 \times g$ for $1 \mathrm{~min}$ before heating for $45 \mathrm{~min}$ at $65{ }^{\circ} \mathrm{C}$ in a constant temperature water bath, with the temperature then being raised to $95^{\circ} \mathrm{C}$ for $10 \mathrm{~min}$. Samples were then centrifuged at $12,000 \times g$ for $3 \mathrm{~min}$, before collecting the supernatant and storing it at $4{ }^{\circ} \mathrm{C}$.
Fig. 1 Beetle sampling locations. (1) Dalian $\left(121^{\circ} 61^{\prime} \mathrm{E}\right.$, $\left.38^{\circ} 88^{\prime} \mathrm{N}\right)$, Liaoning Province; (2) Qingdao $\left(120^{\circ} 51^{\prime} \mathrm{E}, 36^{\circ}\right.$ $\left.24^{\prime} \mathrm{N}\right)$, Shandong Province; (3) Zhashui $\left(109^{\circ} 13^{\prime} \mathrm{E}, 33^{\circ} 61^{\prime}\right.$ N), Shannxi Province; (4) Foping $\left(107^{\circ} 98^{\prime} \mathrm{E}, 33^{\circ} 73^{\prime} \mathrm{N}\right)$, Shanxi Province; (5) Linshui $\left(107^{\circ} 01^{\prime}\right.$ E, $30^{\circ} 06^{\prime} N$ ), Sichuan Province; (6) Huangshan $\left(118^{\circ} 22^{\prime}\right.$ E, $29^{\circ} 66^{\prime} \mathrm{N}$ ), Anhui Province; (7) Renhuai $\left(106^{\circ} 36^{\prime} \mathrm{E}, 27^{\circ} 85^{\prime}\right.$ N), Guizhou Province

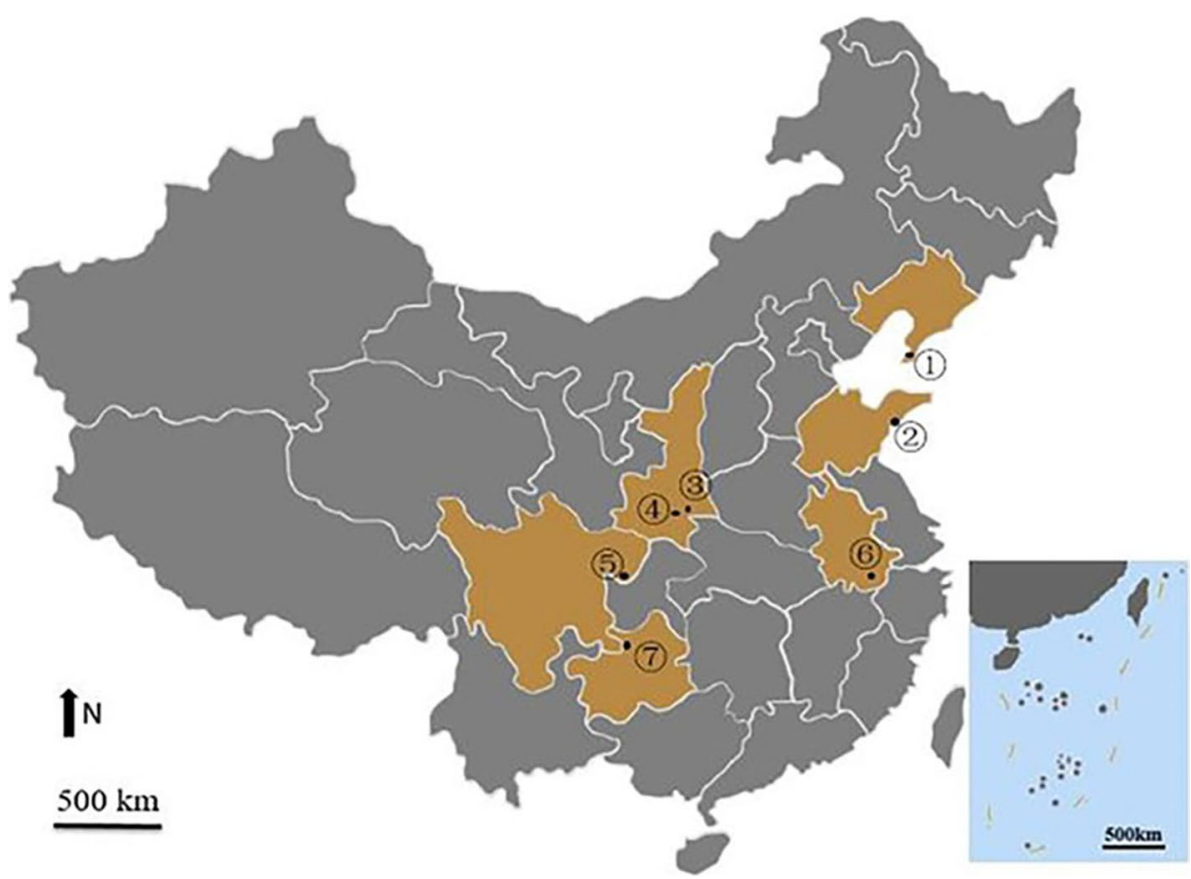


The 10- $\mu \mathrm{L}$ detection mixture consisted of $3.5 \mu \mathrm{L}$ of the supernatant, $5 \mu \mathrm{L}$ of Premix Ex Taq (Takara, Dalian, China), and $1.5 \mu \mathrm{L}$ of a mixture of probe (5'-TGCAC GTTGT GACAG TCGT-3') and primers (F: 5'-GAGCA GAAAC GCCGA CTT-3', R: 5'-CGTAA AACAG ATGGT GCCTA-3') (GAQSIQ 2017) in the PCR tube which was centrifuged at $2000 \times g$ for $30 \mathrm{~s}$. The detection mixture was analyzed with LineGene K Plus Real-Time PCR Detection System (FQD-48A, Hangzhou Bioer Technology Co. Ltd. Hangzhou, China) for PWN (constant temperature: $95{ }^{\circ} \mathrm{C}$ for $20 \mathrm{~s} ; 40$ cycles at $95{ }^{\circ} \mathrm{C}$ for $15 \mathrm{~s}$, and $60{ }^{\circ} \mathrm{C}$ for $20 \mathrm{~s}$ ).

\section{Results}

There were 8830 beetles belonging to 29 species collected from the PWD-affected areas in the six provinces (Table 1).

Twelve species were collected in Qingdao, the most frequent were A. rusticus, which accounting for $72 \%$ of the total, and M. alternatus, accounting for $25 \%$. Ten species were collected in Dalian. Of these, there were 388 specimens (65\%) of A. rusticus, 105 (18\%) of M. alternatus and $51(8.6 \%)$ of $M$. saltuarius, making them the most frequent beetle species in this PWD-affected area. In Huangshan, nine species were collected, the major ones were $M$. alternatus, accounting for $85 \%$ and A. griseus, accounting for $12 \%$. Seventeen species were collected in Shaanxi Province (Foping and Zhashui), eleven in Zhashui, where $M$.
Table 1 Species of beetle collected in pine wilt diseaseaffected areas in six provinces

\begin{tabular}{|c|c|c|c|c|c|c|c|}
\hline \multirow[t]{3}{*}{ Species } & \multicolumn{7}{|c|}{ Number of beetles collected } \\
\hline & \multirow[t]{2}{*}{$\mathrm{SD}$} & \multirow[t]{2}{*}{$\mathrm{LN}$} & \multirow[t]{2}{*}{$\mathrm{AH}$} & \multicolumn{2}{|l|}{ SX } & \multirow[t]{2}{*}{$\mathrm{SC}$} & \multirow[t]{2}{*}{ GZ } \\
\hline & & & & Foping & Zhashui & & \\
\hline Calolepta permutans Pascoe & & & & 5 & & & \\
\hline Acalolepta sublusca Thomson & 2 & & & & & 4 & \\
\hline Acanthocinus griseus Fabricius & & 6 & 164 & & 12 & 32 & 48 \\
\hline Anoplophora chinensis Forster & 5 & 9 & 7 & & 1 & & 3 \\
\hline Apriona rugicolliis Chevrolat & 8 & 4 & & & & & 5 \\
\hline Arhopalus rusticus Linnaeus & 3040 & 388 & 16 & & 9 & 15 & 12 \\
\hline Aristobia hispida Saunders & & & & 1 & & & \\
\hline Aromia bungii Faldermann & 20 & 12 & 2 & & & & \\
\hline Chloridolum thaliodes Bates & & & & & & 1 & \\
\hline Dorysthenes granulosus Thomson & 1 & & & & & & \\
\hline Lamiomimus gottschei Kolbe & & 5 & & & 3 & & 2 \\
\hline Megopis sinica White & 12 & 11 & & & & & 7 \\
\hline Mesosa myops Dalmsn & & & & 3 & & & \\
\hline Monochamus alternatus Hope & 1073 & 105 & 1138 & 618 & 865 & 371 & 208 \\
\hline Monochamus nigromaculatus Gressitt & & & & & 323 & & \\
\hline Monochamus saltuarius Gebler & & 51 & & & & & \\
\hline Monochamus sparsutus Fairmaire & & & 2 & & 3 & & \\
\hline Olenecamptus cretaceus marginatus Schwarzer & & & 3 & 6 & & & \\
\hline Paraleprodera diophthalma Pascoe & & & & 2 & 9 & & \\
\hline Pogonocherus dimidiatus Blessig & & & & & & 8 & \\
\hline Purpuricenus petasifer Fairm & & 2 & & & 1 & & \\
\hline Purpuricenus temminckii Guerin & & & & & & 2 & \\
\hline Spondylis buprestoides Linnaeus & & & 5 & 7 & & & \\
\hline Semanotus sinoauster Gressit & 70 & & & & & 17 & \\
\hline Trirachys orientalis Hope & 1 & & & & & & \\
\hline Uraecha angusta Pascoe & & & 2 & 3 & 52 & & \\
\hline Uraecha yunnana Breuning & & & & 5 & & & \\
\hline Xylotrechus magnicollis Fairmaire & 1 & & & & 1 & & \\
\hline Xylotrechus quadripes Cheyrolat & 1 & & & & & & \\
\hline Total number & 4234 & 593 & 1339 & 650 & 1279 & 450 & 285 \\
\hline
\end{tabular}

SD: Qingdao, Shandong Province; LN: Dalian, Liaoning Province; AH: Huangshan, Anhui Province; SX: Shaanxi Province; SC: Linshui, Sichuan Province; GZ: Renhuai, Guizhou Province 
alternatus accounting for $68 \%$ of the total and Monochamus nigromaculatus for $25 \%$. Nine species were collected in Foping with M. alternatus accounting for 95\%. Only three species (M. alternatus, Uraecha angusta, and Paraleprodera diophthalma) were found in each of Zhashui and Foping. Eight species were collected in Linshui, with M. alternatus the most abundant, accounting for $82 \%$. Seven species were collected in Renhuai, with M. alternatus the most abundant, accounting for $73 \%$, followed by A. griseus with 48 specimens $(17 \%)$.

In this study, all the beetle species were examined to determine whether they were PWN carriers. The results are shown in Table 2, in which eight (supplementary Figs. S2-S9) were carriers, namely Aromia bungii, A. griseus, A. rusticus, M. alternatus, M. nigromaculatus, M. saltuarius, $U$. angusta, and Semanotus sinoauster. For the first time, $M$. nigromaculatus, $S$. sinoauster, and $U$. angusta were identified as PWN carriers (qPCR results: supplementary Figs. S10-S12), and for the first time in China, A. rusticus was identified as a PWN carrier (qPCR results: supplementary Fig. S13).

\section{Discussion}

This study is the first worldwide report of PWN detected in M. nigromaculatus, S. sinoauster and U. angusta. M. nigromaculatus is a member of Monochamus spp. (Cerambycidae), to which all previously identified PWN vectors belong (Zhang et al. 2007). Therefore, it is very likely that $M$. nigromaculatus is a vector insect. It is also one of the most important beetle species in the sampling area, accounting for $25 \%$ of the total number collected. Therefore, it should be further studied with the ultimate aim of improving
Table 2 Beetle species identified as pine wood nematode (PWN) carriers

\begin{tabular}{|c|c|c|c|}
\hline Species of beetles & $\begin{array}{l}\text { Number of beetles } \\
\text { examined }\end{array}$ & $\begin{array}{l}\text { Number of beetles } \\
\text { carrying PWN }\end{array}$ & Percentage $(\%)^{\mathrm{a}}$ \\
\hline Acalolepta permutans & 5 & 0 & 0 \\
\hline Acalolepta sublusca & 6 & 0 & 0 \\
\hline Acanthocinus griseus & 30 & 4 & 13 \\
\hline Anoplophora chinensis & 25 & 0 & 0 \\
\hline Apriona rugicolliis & 17 & 0 & 0 \\
\hline Arhopalus rusticus* & 30 & 6 & 20 \\
\hline Aromia bungii & 30 & 3 & 10 \\
\hline Aristobia hispida & 1 & 0 & 0 \\
\hline Chloridolum thaliodes & 1 & 0 & 0 \\
\hline Dorysthenes granulosus & 1 & 0 & 0 \\
\hline Lamiomimus gottschei & 10 & 0 & 0 \\
\hline Megopis sinica & 30 & 0 & 0 \\
\hline Mesosa myops & 3 & 0 & \\
\hline Monochamus alternatus & 30 & 9 & 30 \\
\hline Monochamus nigromaculatus ${ }^{\mathrm{b}}$ & 30 & 6 & 20 \\
\hline Monochamus saltuarius & 30 & 7 & 23 \\
\hline Monochamus sparsutus & 5 & 0 & 0 \\
\hline Olenecamptus cretaceus marginatus & 9 & 0 & 0 \\
\hline Paraleprodera diophthalma & 11 & 0 & 0 \\
\hline Pogonocherus dimidiatus & 8 & 0 & 0 \\
\hline Purpuricenus petasifer & 3 & 0 & 0 \\
\hline Purpuricenus temminckii & 2 & 0 & 0 \\
\hline Semanotus sinoauster ${ }^{\mathrm{b}}$ & 30 & 3 & 10 \\
\hline Spondylis buprestoides & 12 & 0 & 0 \\
\hline Trirachys orientalis & 1 & 0 & 0 \\
\hline Uraecha angusta ${ }^{\mathrm{b}}$ & 30 & 5 & 17 \\
\hline Uraecha yunnana & 5 & 0 & 0 \\
\hline Xylotrechus magnicollis & 2 & 0 & 0 \\
\hline Xylotrechus quadripes & 1 & 0 & 0 \\
\hline
\end{tabular}

${ }^{\text {a }}$ Percentage carrying PWN to the total examined

${ }^{b}$ Newly discovered species that carry PWN 
the prevention and control of PWD in that area. However, very few studies have investigated $M$. nigromaculatus, so it is necessary to study its habits and determine whether it can transmit PWN. In addition, U. angusta belong to Uraecha spp. (Cerambycidae) and S. sinoauster to Semanotus spp. (Cerambycidae) (Hua et al. 2009). Although these two species do not belong to the Monochamus genus, their host plants include members of the Pinaceae (Hua et al. 2009), and therefore it would be important to determine whether these two potential vectors can transmit PWN.

Monochamus alternatus, the Japanese pine sawyer, is the main vector responsible for the transmission of the pine wood nematode in China (Ning et al. 2004), and thus it is the main target vector for the prevention and control of PWD. In this study, analysis showed that the distribution of M. alternatus was very wide, occurring across all PWDaffected areas in the six provinces, and it accounted for high percentages of the specimens collected. M. alternatus was dominant among the species collected in the PWD-affected areas in Anhui (85\%), Sichuan (82\%) and Guizhou (73\%) and Shannxi provinces (71\%), reflecting to some extent the severity of PWD in these areas. However, the proportion of $M$. alternatus among the species collected in Liaoning (18\%) and Shandong provinces (25\%) were low. The relative distribution of $M$. alternatus in China is more towards the south and less towards the north (Table 1). A previous study had reported that cold stress may influence the persistence of populations of $M$. alternatus in regions north of $30^{\circ} \mathrm{N}$ and south of $30^{\circ} \mathrm{S}$, so the effective accumulated temperature might limit the spread of M. alternatus (Song and Xu 2006).

Arhopalus rusticus is a highly devastating trunk-boring longhorn beetle that causes considerable damage to trees, particularly members of the Pinaceae and Taxodiaceae families, Cupressus spp. and Quercus spp., as well as to the Alnus cremastogyne Burk. (Bradbury 1998; Wang et al. 2016). Zhao et al. (2004) noted that A. rusticus is the most damaging trunk-boring insect that carries of Bursaphelenchus mucronatus, a nematode species closely related B. xylophilus, but it is not clear whether it can carry B. xylophilus. However, this study showed that $20 \%$ of A. rusticus specimens from PWD-affected area carried PWN. This result is similar to that reported in previous studies that suggested that $A$. rusticus can carry PWN (Linit et al. 1983) and is a potential vector of PWN (Jurc et al. 2012). Previous studies extracted PWN from A. rusticus and that it might spread PWN (Mamiya and Enda 1972; Ridley et al. 2001). In this study, A. rusticus was identified for the first time in China as a PWN carrier. A. rusticus specimens were collected from all six provinces and it was the major beetle species in Liaoning and Shandong Provinces. However, the numbers in the other four provinces were lower, possibly due to different environments, with low numbers in inland areas and higher numbers in coastal areas. Whether this phenomenon is found everywhere remains to be further studied. It is not known if A. rusticus transmits PWN, but further research is merited because of the high abundance of this beetle. Additional studies should focus on its habits.

Acanthocinus griseus is a carrier of PWN in Japan and China (Kobayashi et al. 1971; Xu et al. 1993), and host plants include Pinus koraiensis Sieb., Pinus tabuliformis Carr., Picea jezoensis Carr., Pinus armandii Franch., Pinus massoniana Lamb., Picea asperata Mast., Juglans regia L.; Quercus spp. and Populus spp. (Hua et al. 2009). In this study, Arhopalus griseus specimens were collected from five provinces and it was one of the main beetle species in the Anhui PWD-affected area. Therefore, it is necessary to study the habits of this beetle to determine whether it can transmit PWN. M. saltuarius is an important vector of PWN in Japan (Kobayashi et al. 1984) and Korea (Han et al. 2007) and a recent study found that it can transmit PWN in China (Yu and Wu 2018). Wang et al. (1985) collected an individual of A. bungii from a Pinus thunbergii Parl. $\log$ and this beetle carried 275 individual PWNs. In this study, 13\% of A. bungii examined carried PWN. Members of the Pinaceae are not included among the host plants of $A$. bungii (Hua et al. 2009) and did not feed on Pinaceae in the laboratory. Whether $A$. bungii will oviposition in Pinaceae, emerge and carry pine wood nematodes needs to be further studied. Other beetles that can carry PWN are from the Lamiinae family, but A.bungii and S. sinoauster are from the Cerambycinae and A. rusticus from the Aseminae. Therefore, beetles belonging to Cerambycinae and Aseminae should be evaluated.

It has been found that latitude has a considerable impact on the distribution of biological species (Stevens 1989). In this study, the overall species, number and the major species collected varied greatly among the six provinces. In addition, the species collected varied among different neighboring regions. Seventeen different beetle species were detected in the PWD-affected areas in Zhashui and Foping, (only approximately $100 \mathrm{~km}$ apart), in Shaanxi Province, but only M. alternatus, $P$. diophthalma, and U. angusta were found in both areas. In spite of their proximity, environmental differences presumably resulted in the differences in beetle species present in the two regions. Both are in the Qinling Mountains with complex topography and climatic environments. In addition, there were differences in distribution numbers of the same species in different regions (Song and $\mathrm{Xu}$ 2006). For example, the abundance of A. rusticus was low in inland areas but high along the coast, whereas M. alternatus had the opposite distribution pattern. Studies have shown that climate is one of the main factors that restricts the distribution, growth, and reproduction of living organisms (Parmesan and Yohe 2003). Moreover, increasing evidence suggests that temperature increases, changes in precipitation patterns, and other climate extremes may have major impacts on biodiversity (Parmesan and Yohe 2003; 
Root et al. 2003). Thus, climate differences in coastal and inland areas, as well as changes in latitude from south to north, may explain the different beetle distributions identified in this study.

Only PWD-affected areas in some provinces were investigated in this study and it was not comprehensive in terms of beetle species collected and examined for PWN. In future research, the scope of this research will be expanded in order to track and investigate the dynamic changes in beetle populations in PWD-affected areas, as well as to determine the life habits of the major beetle species and their relationships with and ability to transmit PWN.

\section{Conclusions}

Monochamus nigromaculatus, S. sinoauster, and U. angusta were identified as pine wood nematode (PWN) carriers for the first time worldwide, and, for the first time in China, $A$. rusticus was identified as a PWN carrier. The species, number and major species of beetle collected varied considerably among the various PWD-affected areas in this study. The species collected varied among different neighboring regions and there were differences in distributions of the same species among different regions.

Acknowledgements The authors acknowledge the support of the Forestry Bureaus of Dalian, Qingdao, Huangshan, Renhuai, Linshui, Zhashui and Foping. The authors are grateful to the Area Editor and reviewers whose comments have contributed to improving the quality of this paper.

Open Access This article is licensed under a Creative Commons Attribution 4.0 International License, which permits use, sharing, adaptation, distribution and reproduction in any medium or format, as long as you give appropriate credit to the original author(s) and the source, provide a link to the Creative Commons licence, and indicate if changes were made. The images or other third party material in this article are included in the article's Creative Commons licence, unless indicated otherwise in a credit line to the material. If material is not included in the article's Creative Commons licence and your intended use is not permitted by statutory regulation or exceeds the permitted use, you will need to obtain permission directly from the copyright holder. To view a copy of this licence, visit http://creativecommons.org/licenses/by/4.0/.

\section{References}

Bradbury PM (1998) The effects of the burnt pine longhorn beetle and wood-staining fungi on fire damaged Pinus radiata in Canterbury. N Z J For 43:28-31

Chai XM, Jang P (2003) Occurrence and control of pine wilt disease. China Agriculture Press, Beijing

Chen FM, Ye JR, Wu XQ (2007) Detection technique of Bursaphelenchus xylophilus using real time PCR. J Nanjing For Univ 31(4):121-124 (in Chinese)
GAQSIQ (2017) Technical regulation for molecular detection of Bursaphelenchus xylophilus (Steiner and Buhrer) Nickle. China Zhijian Publishing House, Beijing

Han JH, Yoon CM, Shin SC, Kim GH (2007) Seasonal occurrence and morphological measurements of pine sawyer, Monochamus saltuarius adults (Coleoptera: Cerambycidae). J Asia-Pacific Entomol 10(1):63-67

Hua LZ, Nara H, Saemulson GA, Langafelter SW (2009) Iconography of Chinese longicorn beetles (1406 Species) in Color. Sun Yat-sen University Press, Guangzhou

Jurc M, Bojovic S, Mercedes FF, Jurc D (2012) The attraction of cerambycids and other xylophagous beetles, potential vectors of Bursaphelenchus xylophilus, to semio-chemicals in Slovenia. Phytoparasitica 40(4):337-349

Kim DS, Lee SM, Chung YJ (2003) Emergence ecology of Japanese pine sawyer, Monochamus alternatus (Coleoptera:Cerambycidae), a vector of pinewood nematode Bursaphelenchus xylophilus. Korean J Appl Entomol 42(4):307-313

Kobayashi F, Hosoda R, Okuda M, Taketani A (1971) Extraction of Bursaphelenchus liginicolus from beetles. J Kansai Branch Jpn For Soc 22:137-139

Kobayashi F, Yamane A, Ikeda T (1984) The Japanese pine sawyer beetle as the vector of pine wilt disease. Ann Rev Entomol 29(1):115-135

Linit MJ, Kondo E, Smith MT (1983) Insects associated with the pinewood nematode, Bursaphelenchus xylophilus (Nematoda: Aphelenchoididae). Missouri Environ Entomol 12(2):467-470

Mamiya Y, Enda N (1972) Transmission of Bursaphelenchus lignicolus (Nematoda: Aphelenchoididae) by Monochamus alternatus (Coleoptera: Cerambycidae). Nematologica 18(2):159-162

Ning T, Fang YL, Tang J, Sun JH (2004) Advances in research on Bursaphelenchus xylophilus and its key vector Monochamus spp. Entomol Knowl 41(2):97-104

Parmesan C, Yohe G (2003) A globally coherent fingerprint of climate change impacts across natural systems. Nature 421(6918):37-42

Ridley G, Bain J, Dick M (2001) Exotic nematode found in pine trees in Melbourne. Victoria N Z J For 46(1):41-42

Root TL, Price JT, Hall KR, Schneider SH, Rosenzweig C, Pounds JA (2003) Fingerprints of global warming on wild animals and plants. Nature 421(6918):57-60

Song HM, Xu RM (2006) Global potential geographical distribution of Monochamus alternatus. Chin Bull Entomol 43(4):535-539 (in Chinese)

Sousa E, Bonifácio L, Pires J, Penas AC, Mota M, Bravo MA, Naves P (2001) Bursaphelenchus xylophilus (Nematoda; Aphelenchoididae) associated with Monochamus galloprovincialis (Coleoptera; Cerambycidae) in Portugal. Nematology 3(1):89-91

Stevens GC (1989) The latitudinal gradient in geographical range: how so many species coexist in the tropics. Am Nat 133(2):240-256

Togashi K, Shigesada N (2006) Spread of the pinewood nematode vectored by the Japanese pine sawyer: modeling and analytical approaches. Popul Ecol 48(4):271-283

Vicente C, Espada M, Vieira P, Mota M (2012) Pine wilt disease: a threat to European forestry. Eur J Plant Pathol 133(1):89-99

Wang HT, Yu N, Wang DF, Hou R, Liu ZY, Lu XP (2016) Control efficiency of several pollution-free techniques against Arhopalus rusticus (L.) (Coleoptera: Cerambycidae). Chin J Bio Control 32(5):666671 (in Chinese)

Wang YY, Shi YL, Zhou XS, Bai GH, Liu J (1985) Preliminary observation on the pathogenesis of pine wilt disease of Pinus thunbergii in Nanjing. For Pest Dis 2:15-17 (in Chinese)

Xu FY, Yang BJ, Minghong G (1993) Investigation of vector insects of pine wood nematode. For Pest Dis 2:20-21 (in Chinese)

Yang BJ, Pan HY, Tang J (2003) Pine wood nematode disease. Forestry Publishing House, Beijing 
Yu HY, Wu H (2018) Discovery of new host plant and new vector of Bursaphelenchus xylophilus in Liaoning. For Pest Dis 37(5):61 (in Chinese)

Zhang JJ, Zhang RZ, Chen JY (2007) Species and their dispersal ability of Monochamus as vectors to transmit Bursaphelenchus xylophilus. J Zhejiang For Coll 24(3):350-356 (in Chinese)

Zhang S, Lin SQ, Meng FX, Wu M, Wang CS (2017) Nematode (Enoplida) diversity in sediment samples collected from the clarion-clipperton fracture zone. Axta Ecol Sinica 37(5):1630-1638

Zhao BG, Futai K, Sutherland JR, Yuko T (2008) Pine wilt disease. Springer, Tokyo
Zhao JN, Yu SM, Yao JF, Lin CC, Ding DG, Wang HJ (2004) PWN risk assessment in Huangshan scenic area. For Res 17(1):72-76

Publisher's Note Springer Nature remains neutral with regard to jurisdictional claims in published maps and institutional affiliations. 